\title{
Online Learning Acceptance Model during Covid-19: An Integrated Conceptual Model
}

\author{
Qasem Kharma ${ }^{1}$, Kholoud Nairoukh ${ }^{2}$, AbdelRahman Hussein ${ }^{3}$ \\ Mosleh Abualhaj ${ }^{4}$, Qusai Shambour ${ }^{5}$ \\ Faculty of Information Technology \\ Al-Ahliyya Amman University \\ Amman, Jordan
}

\begin{abstract}
Because of Covid-19, many countries shutdown schools in order to prevent spreading the virus in their communities. Therefore, schools have opted to use online learning technologies that support distance learning for students. As consequences, Ministry of Higher Education and Scientific Research encourages higher education institutes to adopt blended learning in their programs. However, different students react in different ways to online learning. Some students were able to make productive use of online learning strategies more than others. A conceptual model based on 15 variables was constructed based on UTAUT2, TAM, and other models to investigate and to study the factors that affect students' acceptance of online learning. 29 hypotheses were investigated to study the relationships among the variables that affect online learning acceptance and online learning community building in Al-Ahliyya Amman University. The collected responses were analyzed using a structural equation modeling (SEM) approach. SPSS and AMOS were used to analyze the data.
\end{abstract}

Keywords-Online learning; technology acceptance; learning assistance; learning community building assistance

\section{INTRODUCTION}

Since Covid-19 (Coronavirus) started spreading, many countries decided to shutdown schools and move to online learning solutions $[1,2]$. Moving to distance learning because of the virus became necessary in order to keep providing education to students. Different distance learning paradigms were implemented to support distance learning such as livestreaming lectures [3], the use of Massive Open Online Courses (MOOC) [4], and the use of worksheets and animations [5]. Additionally, some educational gamification [6, 7] websites and computer applications were adapted to support online learning. Unfortunately, not all students accept the online learning in place of face-to-face classes.

Based on the online learning feedback during Covid-19, Ministry of Higher Education and Scientific Research developed a plan to adopt online and blended learning in the higher education institutes. As consequences a three-year action plan (2021-2023) was developed to manage adapting synchronized and asynchronized online learning to be blended in higher education. The plan included training faculty members from private and public university. However, moving from traditional lecture-led classes to online learning would cause to move from lecture-centric to learning-centric paradigms. Therefore, students need also to be training and to adapt to the new learning paradigms.

Although the members of Generation $\mathrm{Z}$, who are familiar with various technologies accessing the internet, are the majority of students, it is very important to study the factors that affect their intention to use their technical knowledge in digital learning [8]. It is very important to know the factors that are affecting users' adoption of technologies in order to achieve the objectives of the proposed technology. Many models, such as the Unified Theory of Acceptance and Use of Technology (UTAUT) [9, 10], were proposed to explain users' behavior in utilizing technologies. However, the factors that affect the use of a technology are vary based on the environment [11].

In this research, a model is constructed using 15 variables to investigate its effects on the online learning in Al-Ahliyya Amman University. The model was developed based on UTAUT2 [10], the conceptual TAM (Technology Acceptance Model) [12-15], and a conceptual model proposed by Vululleh [16]. Based on the defined variables, the research model was constructed, and 29 hypotheses were investigated and analyzed using a structural equation modeling (SEM) approach in SPSS and AMOS.

\section{LITERATURE REVIEW}

One of the widely applied models to study the factors that affect using a technology is UTAUT [9]. It was developed by investigating eight different models. The eight models are the model of PC utilization (MPCU) [17], social cognitive theory (SCT) [18], Technology Acceptance Model (TAM) [19], innovation diffusion theory (IDT) [20], the combined theory of planned behavior/technology acceptance model (C-TPBTAM) [21], and the motivational model (MM) [22]. As a result, UTAUT was formulated based on four factors: performance expectancy (PE), effort expectancy (EE), social influence (SI), and facilitating conditions (FC). Also, UTAUT considered four moderators: gender, age, experience, and voluntariness of use. In 2012, UTAUT was extended to UTAUT2 [10] by adding hedonic motivation, price value, and habit factors to the model. Later, the Values-Enhanced Technology Adoption (VETA) model [23] extended UTAUT2 by adding new variables to UTAUT2 variables. Although UTAUT and UTAUT2 are widely used to study the acceptance of technology, they need to be adapted to the context of eLearning. 
Islam [13] investigates the effects of learning management systems (LMS) on achieving learning outcomes by developing a model based on TAM. The model suggests that LMS may assist students in learning and building a collaborative network in hybrid courses which combine both face-to-face education and online learning. Learning assistance and perceived community building assistance were added to TAM. The model was formulated using five factors: Perceived Usefulness, Perceived Ease of Use, e-Learning Use, Perceived Learning Assistance, and Perceived Community Building Assistance. The model did not consider the design of online courses nor the factors which can affect the learner community building.

Since online learning is usually web browser-based or based in mobile applications, a model developed by Liu, et al. [12] added new variables that may affect the acceptance of online learning to TAM. The new variables are related to the technology design and the user experience with technology. The model used the following constructs: Perceived Usefulness, Perceived Ease of Use, and Intension to Use (from TAM). The following constructs were developed: Online Course Design, User-Interface Design, Previous Online Learning Experience, and Perceived Interaction. The model integrates the effects of online course design and interface design with TAM. However, the model did not consider the effects of the variables such as hedonic motivation, price value, community building and habit factors.

Vululleh [16] studied students' acceptance of e-learning technology in Liberia. The research model was based on TAM, which proposes that users' Behavioral Intention to adopt a technology is controlled by their beliefs of Perceived Usefulness (PU) and Perceived Ease of Use (PEOU). Additionally, the model extended TAM by adding two factors, Social Influence (SI) and Quality of Life (QL). Therefore, the conceptual model studied the effects of four factors: PU, PEOU, SI, and QL on the Behavior Intention (BI) to use elearning. Like Liu, et al. [12] and Islam [13], Vululleh [16] proposed a model based on TAM. Factors such as design, interface and community building were not considered.

Some models studied the differences of acceptance in different environment. For instance, Lee [14] examines the difference between Korean and American students’ perceptions of online education. The model was based on TAM using the two factors Perceived Usefulness (PU) and Perceived Ease of Use (PEOU), and adding the two factors Perception of Online Learning Acceptance and Student Satisfaction (OLAS) and Online Education Support Service Quality (PSQ). The model found that the (PSQ) directly influenced behavioral intention toward online learning acceptance and student satisfaction. However, the impact of service quality on the behavioral intension toward e-learning in different cultures was limited. The model investigates the direct and indirect effects of PSQ on PLAS; however, more variables such as design, interface and community building need to be considered.

The model proposed by Ratna and Mehra [15] examines the behavioral intention of the university students in India for using e-learning. The model was based on TAM using the factors of Gender, Student Major, and Monthly Family Income. It examines the applicability of TAM among university students in India and found that Perceived Ease of Use (PEOU) has a significant effect on Perceived Usefulness (PU), Attitude (ATT), Behavioral Intention (BI) and Actual Use (AU). Also, PU has a significant effect on ATT, BI, and AU. Moreover, ATT has a significant effect on Intention to Use (INT). Finally, this model found that BI has a significant effect on AU. Like the aforementioned models, this model is also based on TAM and limited to study the effects of four variables only.

\section{MODEL DEVELOPMENT}

The proposed model is based on 15 variables that were utilized in several studies [9, 10, 12-16, 19, 24, 25] to investigate the factors that affect the adoption of technologies:

1) Performance Expectancy is how technology benefits users to perform certain activities [10], and Perceived Learning Assistance (PLA) is how an online learning component can help the individual's learning [13]. Therefore, in our research model, these two factors are combined into one factor.

2) Perceived Community Building Assistance (PCBA) refers how the online learning helps individuals to have social interactions with others [13]. Liu, et al. [12] defines Perceived Interaction as interpersonal interaction and human-system interaction. The interpersonal interactions include interactions with peers and instructors. In our conceptual model, we opt to include Perceived Community Building Assistance and interpersonal interaction into one factor.

3) Online Course Design (OCD) refers to the types and quality of the materials that can be included in the online course [12]. Since the online course is web browser-based or based in a mobile application, it can include different types of material such as images, animation, and video. Therefore, the quality of these materials can have great impact on users.

4) When developing software, User-Interface Design (UID) plays crucial role in the success of the software. In online course, User-Interface Design refers the organization and arrangement of the online course content and visual design [12].

5) Effort Expectancy is how ease the use of the technology affects users [10]. Effort Expectancy is also called by other researchers such as Liu, et al. [12] as Perceived Ease of Use. Hence, only one of them (PEU) is included in our conceptual model to find the effects of ease of use of e-learning technology on the intention to use it.

6) Social Influence (SI) is how other people, such as family and friends, influence users' decisions to adopt the technology [10].

7) Facilitating Conditions are the resources and the support that are available to the user to use the technology [9]. These include both physical and environmental factors [26] that help students to learn using online resources. In our model, the Perceived Service Quality (PSQ) variable represents all the factors that help the students to use the online resources. 
8) Hedonic Motivation (HM) is defined as the fun, enjoyment, or pleasure that the users of a technology can have [10]. This variable was not in UTAUT [9], but it was added to UTAUT2 [10] and was considered the most important added variable to UTAUT2 [27].

9) Quality of Life (QoL) is how online learning processes can affect the students' faith [26]. This includes saving time and costs when using or downloading the online learning materials.

10)Price Value (PV) is the monetary costs assigned with the use of the technology [10].

11)Habit and Experience (Habit) is the user's ability to use the technology without the need for training because of learning and previous experience [10].

12)Behavioral Intention (BI) measures students' acceptance of online courses in the present and in the future [26].

13)Technological Experience (EXP) represents the skills that students need to use online courses. Martinho, et al. [24] classify Technological Experience into two external variables: Base Technological Experience and Advanced Technological Experience. However, since basic computer skills are taught in schools starting from the elementary grades, we opt in the proposed model not to distinguish between Base Technological Experience and Advanced Technological Experience.

14)Perceived Usefulness (PU) is the degree to which students believe that online learning will enhance their job performance [13]. This variable was introduced in TAM [19].

15)Previous Online Learning Experience (OLE) [12] including using technology, internet, and online learning resources can affect learners' intentions to use online learning.

Based on the aforementioned variables, the following hypotheses were proposed.

H1: OLE will positively affect students' BI to use online courses.

H2: OLE will positively affect students' PU of online courses.

H3: OLE will positively affect students' PEU of online courses.

H4: OCD will positively affect students' PU of online courses.

H5: OCD will positively affect students' PEU of online courses.

H6: OCD will positively affect students' PCBA of online courses.

H7: PSQ will positively affect students' PU of online courses.

H8: PSQ will positively affect students' BI to use online courses.

H9: PSQ will positively affect students' PEU of online courses.
H10: UID will positively affect students' PEU of online courses.

H11: UID will positively affect students' PCBA of online courses.

H12: PU of online courses will positively affect students' $\mathrm{BI}$ to use online courses.

H13: PU of online courses will positively affect students' PLA to use online courses.

H14: PU of online courses will positively affect students' PCBA of online courses.

H15: EXP will positively affect students' PU of online courses.

H16: EXP will positively affect students' PEU of online courses.

H17: PEU of online courses will positively affect students' $\mathrm{PU}$ of online courses.

H18: PEU of online courses will positively affect students' BI to use online courses.

H19: PEU of online courses will positively affect students' PLA to use online courses.

H20: PEU of online courses will positively affect students' PCBA of online courses.

H21: SI will positively affect students' PU of online courses.

H22: SI will positively affect students' BI to use online courses.

H23: BI to use online courses will positively affect students' PLA to use online courses.

H24: BI to use online courses will positively affect students' PCBA of online courses.

H25: QoL will positively affect students' BI to use online courses.

H26: HM will positively affect students' BI to use online courses.

H27: PV will positively affect students' BI to use online courses.

H28: Habit will positively affect students' BI to use online courses.

H29: PCBA will positively affect students' PLA to use online courses.

\section{Methodology}

Quantitative methods were utilized, in the form of nonstructured survey questionnaires with closed questions using a 5 -point Likert-type scale where 1 is highly disagree and 5 is highly agree. The questionnaire was constructed of 15 variables and 69 items in total. The items included in the questionnaire were collected from prior studies. Prior to the survey, a pilot study was conducted to assure the reliability and 
validity of the questionnaire. The entire instrument demonstrated acceptable reliability; Cronbach's alpha was 0.962. The questionnaire was randomly distributed to AlAhliyya Amman University students. The final accepted questionnaires for analysis were 462 out of 517 from the submitted responses. The data were analyzed using SPSS version 25 and AMOS version 23.

\section{A. Data Analysis}

There are nine colleges in Al-Ahliyya Amman University: Faculty of Information Technology, Faculty of Pharmacy, Faculty of Architecture \& Design, Faculty of Allied Medical Sciences, Faculty of Arts \& Sciences, Faculty of Engineering, Business School, Faculty of Law, and Faculty of Nursing. The responses, which were used in the analysis according to the colleges, was as followings: Faculty of Information Technology (36\%), Business School (22.7\%), Faculty of Pharmacy (19\%), and the other colleges (22.3\%) (see Table 1).

Faculty of Engineering and Faculty of Pharmacy are fiveyear colleges, while the other colleges are four-year colleges. The responses that were used spanned the following student levels: First Year (24\%), Second Year (25.8\%), Third Year (21.6\%), Fourth Year (17.7\%), and Fifth Year (10.8\%) (see Table 2).

Table 3 illustrates the previous student experience with online courses. 60 students (13\%) had never ever studied with any online course, while 402 (87\%) students had studied using some online courses. 205 students studied one or two online courses. 165 students studied 3 to 5 online courses. 32 students studied 6 or more online courses.

TABLE I. STUDENT DistRIBUTION OVER COLLEGES

\begin{tabular}{|l|l|l|}
\hline College & Frequency & Percent \\
\hline Faculty of Information Technology & 167 & 36.1 \\
\hline Faculty of Pharmacy & 88 & 19.0 \\
\hline Faculty of Architecture \& Design & 21 & 4.5 \\
\hline Faculty of Allied Medical Sciences & 13 & 2.8 \\
\hline Faculty of Arts \& Sciences & 24 & 5.2 \\
\hline Faculty of Engineering & 19 & 4.1 \\
\hline Business School & 105 & 22.7 \\
\hline Faculty of Law & 18 & 3.9 \\
\hline Faculty of Nursing & 7 & 1.5 \\
\hline Total & 462 & 100.0 \\
\hline
\end{tabular}

TABLE II. STUDENT LEVELS

\begin{tabular}{|l|l|l|}
\hline Level & Frequency & Percent \\
\hline First Year & 111 & 24.0 \\
\hline Second Year & 119 & 25.8 \\
\hline Third Year & 100 & 21.6 \\
\hline Fourth Year & 82 & 17.7 \\
\hline Fifth Year & 50 & 10.8 \\
\hline Total & 462 & 100.0 \\
\hline
\end{tabular}

TABLE III. STUDENT EXPERIENCE WITH ONLINE COURSES

\begin{tabular}{|l|l|l|}
\hline Online Course & Frequency & Percent \\
\hline Never studied online course & 60 & 13.0 \\
\hline studied 1-2 online courses & 205 & 44.4 \\
\hline studied 3-5 online courses & 165 & 35.7 \\
\hline Studied more than 6 online courses & 32 & 6.9 \\
\hline Total & 462 & 100.0 \\
\hline
\end{tabular}

\section{B. Hypotheses Testing}

The model is consisted of 15 variables that were measrured in a questionnare of 69 items. The variable averages (ranging from 3.5 to 3.9) and standard deviations (ranging from 1 to 1.3) are listed in Table 4. The variables Cronbach's Alpha if Item Deleted was ranged from 0.958 and 0.962 . Since total variable Cronbach's Alpha is 0.962, all variables were included in the model and none of them need to be dropped. Many indexes were measured to test the model fitness (see Table 5). Since all the minimum values of the indexes were achieved, the model fits enough to measure the hypotheses. All factor loadings were above 0.6 ; therefore, all items were used in the analysis.

TABLE IV. THE MODEL VARIABLES

\begin{tabular}{|l|l|l|l|}
\hline Variable & Mean & Std. Deviation & $\begin{array}{l}\text { Cronbach's Alpha if } \\
\text { Item Deleted }\end{array}$ \\
\hline PU & 3.4654 & 1.04352 & .959 \\
\hline PEU & 3.4802 & 1.04912 & .959 \\
\hline PLA & 3.5415 & 1.13455 & .959 \\
\hline PSQ & 3.5584 & 1.12182 & .958 \\
\hline EXP & 3.9446 & 1.24697 & .960 \\
\hline PCBA & 3.5361 & 1.10217 & .958 \\
\hline OCD & 3.5000 & 1.16716 & .958 \\
\hline UID & 3.5260 & 1.24651 & .958 \\
\hline OLE & 3.6075 & 1.25583 & .959 \\
\hline SI & 3.5216 & 1.14455 & .958 \\
\hline QoL & 3.5628 & 1.18976 & .958 \\
\hline BIs & 3.6129 & 1.17900 & .958 \\
\hline PV & 3.4726 & 1.19596 & .962 \\
\hline Habit & 3.5476 & 1.07761 & .959 \\
\hline HM & 3.5440 & 1.29309 & .960 \\
\hline
\end{tabular}

TABLE V. MODEL FIT Results

\begin{tabular}{|l|l|l|}
\hline Index & Value & Recommended values \\
\hline Degrees of freedom & 2203 & $>0[17]$ \\
\hline Discrepancy Chi-Squared & 4031 & $>.05[17]$ \\
\hline Relative Chi-Squared & 1.83 & $<5.0[18]$ \\
\hline Comparative Fit Index & 0.915 & $\geq 0.9[18,19]$ \\
\hline Tucker Lewis Index & 0.909 & $\geq 0.9[17,20]$ \\
\hline Incremental Fit Index & 0.915 & $\geq 0.9[17,20]$ \\
\hline $\begin{array}{l}\text { Root Mean Square of Error } \\
\text { Approximation }\end{array}$ & 0.042 & $\leq 0.08[17]$ \\
\hline
\end{tabular}


The 29 hypotheses were tested using AMOS. 15 hypothses were supported while 14 hypothese were rejected. The result is illustrated in Table 6. H17, which states that Perceived Ease of Use of online courses will positively affect students' Perceived Usefulness of online courses, has high impacts; if Perceived Ease of Use goes up by 1 unit, Perceived Usefulness of online courses goes up by 1.204. In addition, if Perceived Ease of Use goes up by 1 unit, PLA goes up by 0.839 unit. Therefore, Perceived Ease of Use is considered a very important factor in online learning.

On the other hand, the effects of the factors in H7, H14, and H18 have negative effects. In H18, Perceived Ease of Use will negatively affect Behavioral Intentions. When Perceived Ease of Use goes up one-unit, Behavioral Intentions goes down by 0.822 . Thus, when the students feel that online courses are too easy to use, they will use them less. In short, H7, H14, and H18 will be stated as following:

H7: Perceived Service Quality negatively affects students' Perceived Usefulness of online courses.

H14: Perceived Usefulness of online courses negatively affects students' Community Building Assistance of online courses.

H18: Perceived Ease of Use of online courses negatively affects students’ Behavior Intention to use online.

TABLE VI. HyPOTHESES TESTING

\begin{tabular}{|c|c|c|c|c|c|c|c|c|}
\hline \multicolumn{4}{|c|}{ Hypotheses } & \multirow{2}{*}{$\begin{array}{c}\text { Estimated } \\
-0.076\end{array}$} & \multirow{2}{*}{$\begin{array}{l}\text { S.E. } \\
0.089\end{array}$} & \multirow{2}{*}{$\begin{array}{l}\text { C.R. } \\
-0.858\end{array}$} & \multirow{2}{*}{$\begin{array}{l}\mathrm{P} \\
0.391\end{array}$} & \multirow{2}{*}{$\frac{\text { Comments }}{\text { Not Supported }}$} \\
\hline H1 & BI & $\leftarrow$ & OLE & & & & & \\
\hline $\mathrm{H} 2$ & $\mathrm{PU}$ & $\leftarrow$ & OLE & 0.041 & 0.074 & 0.559 & 0.576 & Not Supported \\
\hline H3 & PEU & $\leftarrow$ & OLE & 0.003 & 0.055 & 0.054 & 0.957 & Not Supported \\
\hline $\mathrm{H} 4$ & $\mathrm{PU}$ & $\leftarrow$ & OCD & 0.25 & 0.096 & 2.595 & 0.009 & Supported* \\
\hline H5 & PEU & $\leftarrow$ & OCD & 0.332 & 0.109 & 3.057 & 0.002 & Supported* \\
\hline H6 & PCBA & $\leftarrow$ & OCD & 0.684 & 0.169 & 4.034 & $* * *$ & Supported ${ }^{* * *}$ \\
\hline $\mathrm{H} 7$ & $\mathrm{PU}$ & $\leftarrow$ & PSQ & -0.368 & 0.143 & -2.582 & 0.01 & Supported** \\
\hline H8 & BI & $\leftarrow$ & PSQ & 0.362 & 0.193 & 1.87 & 0.062 & Not Supported \\
\hline H9 & PEU & $\leftarrow$ & PSQ & 0.63 & 0.09 & 6.969 & $* * *$ & Supported*** \\
\hline $\mathrm{H} 10$ & PEU & $\leftarrow$ & UID & -0.12 & 0.086 & -1.404 & 0.16 & Not Supported \\
\hline H11 & PCBA & $\leftarrow$ & UID & -0.162 & 0.109 & -1.484 & 0.138 & Not Supported \\
\hline $\mathrm{H} 12$ & $\mathrm{BI}$ & $\leftarrow$ & $\mathrm{PU}$ & 0.565 & 0.243 & 2.33 & 0.02 & Supported* \\
\hline $\mathrm{H} 13$ & PLA & $\leftarrow$ & PU & 0.034 & 0.137 & 0.248 & 0.804 & Not Supported \\
\hline H14 & PCBA & $\leftarrow$ & $\mathrm{PU}$ & -0.286 & 0.141 & -2.025 & 0.043 & Supported* \\
\hline H15 & $\mathrm{PU}$ & $\leftarrow$ & EXP & -0.013 & 0.045 & -0.286 & 0.775 & Not Supported \\
\hline H16 & PEU & $\leftarrow$ & EXP & -0.012 & 0.043 & -0.278 & 0.781 & Not Supported \\
\hline H17 & $\mathrm{PU}$ & $\leftarrow$ & PEU & 1.204 & 0.18 & 6.674 & $* * *$ & Supported*** \\
\hline H18 & $\mathrm{BI}$ & $\leftarrow$ & PEU & -0.822 & 0.401 & -2.052 & 0.04 & Supported* \\
\hline H19 & PLA & $\leftarrow$ & PEU & 0.839 & 0.183 & 4.586 & $* * *$ & Supported $* * *$ \\
\hline $\mathrm{H} 20$ & PCBA & $\leftarrow$ & PEU & 0.653 & 0.165 & 3.963 & $* * *$ & Supported*** \\
\hline H21 & $\mathrm{PU}$ & $\leftarrow$ & SI & -0.142 & 0.095 & -1.497 & 0.134 & Not Supported \\
\hline $\mathrm{H} 22$ & BI & $\leftarrow$ & SI & 0.377 & 0.122 & 3.095 & 0.002 & Supported** \\
\hline $\mathrm{H} 23$ & PLA & $\leftarrow$ & BI & 0.222 & 0.052 & 4.273 & $* * *$ & Supported*** \\
\hline $\mathrm{H} 24$ & PCBA & $\leftarrow$ & BI & 0.059 & 0.066 & 0.892 & 0.373 & Not Supported \\
\hline H25 & $\mathrm{BI}$ & $\leftarrow$ & QoL & 0.388 & 0.085 & 4.589 & $* * *$ & Supported ${ }^{* * *}$ \\
\hline H26 & $\mathrm{BI}$ & $\leftarrow$ & HM & 0.023 & 0.048 & 0.48 & 0.631 & Not Supported \\
\hline $\mathrm{H} 27$ & BI & $\leftarrow$ & PV & -0.073 & 0.046 & -1.605 & 0.109 & Not Supported \\
\hline $\mathrm{H} 28$ & $\mathrm{BI}$ & $\leftarrow$ & Habit & 0.315 & 0.076 & 4.165 & $* * *$ & Supported*** \\
\hline H29 & PLA & $\leftarrow$ & PCBA & -0.041 & 0.082 & -0.496 & 0.62 & Not Supported \\
\hline
\end{tabular}




\section{LIMITATION AND CONCLUSION}

The study was conducted in a private university, AlAhliyya Amman University. Online learning has become a necessity after the spread of Covid-19. Therefore, this study can be extended to include responses from students in different educational institutions, including public and private institutions and K-12 institutions. All responses were collected from students. The study can be extended to collect responses from instructors as well. Finally, the moderator affects, such as age, gender, and experience, were not considered in this study because there studies such as Liao, et al. [21] and Kharma [22] found that there were no significant effects of these moderators in online learning models. However, when extending the study to include different categories of educational institutions, there might be impacts of these moderators on the relations in the model.

The study proposed a theoretical model to investigate the effects of 15 variables on online learning acceptance. Based on these 15 variables, 29 hypotheses were tested. Only 14 hypotheses were supported. The final model is shown in Fig 1.
Four variables: Perceived Usefulness, Social Influence, Quality of Life, and Habit had positive effects on Behavioral Intention to use the online course. The highest estimated beta value of these was of Perceived Usefulness. In other words, in order to increase students' behavioral intention to use an online course, they should know the importance of the online courses in learning. The role of academic advising can help in increasing students' awareness of the usefulness of online learning and how it can affect the learning process by accessing the online material at anytime and anywhere.

Moreover, the study found that the course design and ease of use of the course affect the online collaborative learning. Therefore, in order to enhance peer-learning and grouplearning, the online courses should include in the design simple and easy features that allow students to communicate with their classmates. Additionally, ease of use positively affects students' perceptions of online learning. Hence, the ease of use of online learning components and environment is crucial to increasing students' intent to learn from online learning components and to cooperate with their classmates.

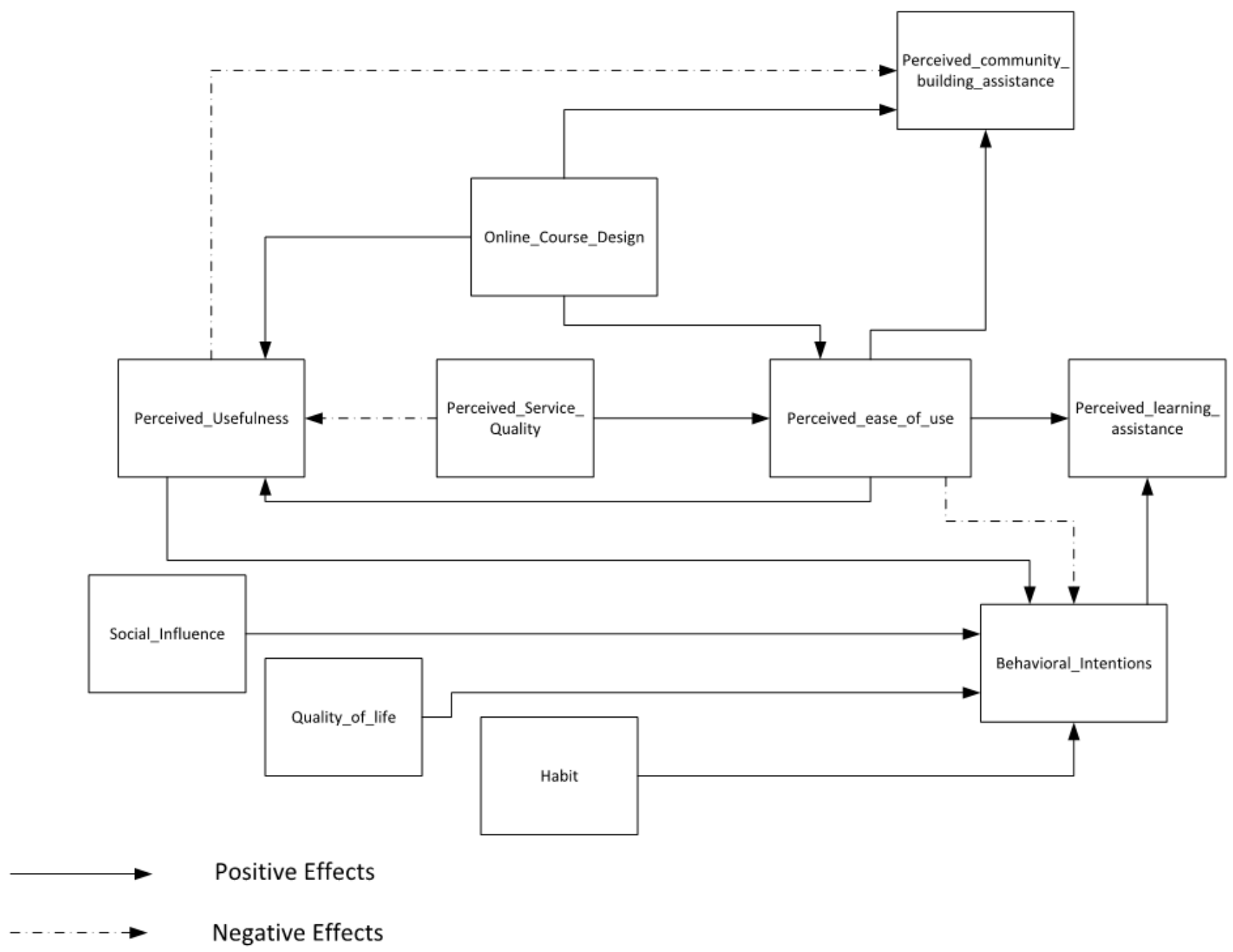

Fig. 1. Final Model. 
Three relations had negative effects in the model. The first one is that the more assistance in using the online course, and more physical requirements to access the online course, the less usefulness the online course has. The second is that the more assistance in using the online course and more physical requirements to access the online course, the less collaboration there is with others. Finally, if the students feel that the online course is too easy, they won't be as interested in the online course. Therefore, the physical requirements and the technical assistance should be minimized. For instance, online courses should use good compression to minimize the usage of internet bandwidth and hardware requirements. Additionally, online courses should not be too easy. The students like some challenges in the learning process.

Finally, the effects of Hedonic Motivation were not supported. This finding agrees with Mehta, et al. [23]. Collegelevel students do not use online learning for fun. However, further investigation is needed to study the effects of Hedonic Motivation in different educational system levels, such as K-12 schools.

\section{REFERENCES}

[1] W. Van Lancker and Z. Parolin, "COVID-19, school closures, and child poverty: a social crisis in the making," The Lancet Public Health, vol. 5, no. 5, pp. e243-e244, 2020.

[2] M. Mossa-Basha et al., "Policies and guidelines for COVID-19 preparedness: experiences from the University of Washington," Radiology, p. 201326, 2020.

[3] A. Sandhu, A. Fliker, D. Leitao, J. Jones, and A. Gooi, "Adding LiveStreaming to Recorded Lectures in a Non-Distributed Pre-Clerkship Medical Education Model," in ITCH, 2017, pp. 292-297.

[4] M. Brown, "Why invest in MOOCs? Strategic institutional drivers," The 2018 OpenupEd trends report on MOOCs, pp. 6-9, 2018.

[5] S. Mahtari, M. Wati, S. Hartini, M. Misbah, and D. Dewantara, "The effectiveness of the student worksheet with PhET simulation used scaffolding question prompt," in Journal of Physics: Conference Series, 2020, vol. 1422, no. 1: IOP Publishing.

[6] D. Dicheva, C. Dichev, G. Agre, and G. Angelova, "Gamification in education: A systematic mapping study," Journal of Educational Technology \& Society, vol. 18, no. 3, 2015.

[7] J. Majuri, J. Koivisto, and J. Hamari, "Gamification of education and learning: A review of empirical literature," in Proceedings of the 2nd international GamiFIN conference, GamiFIN 2018, 2018: CEUR-WS.

[8] S. F. Persada, B. A. Miraja, and R. Nadlifatin, "Understanding the Generation Z Behavior on D-Learning: A Unified Theory of Acceptance and Use of Technology (UTAUT) Approach," International Journal of Emerging Technologies in Learning (iJET), Generation Z; Digital Learning; UTAUT; Confirmatory Factor Analysis; Behavior Intention vol. 14, no. 05, p. 20, 2019-03-14 2019, doi: 10.3991/ijet.v14i05.9993.

[9] V. Venkatesh, M. G. Morris, G. B. Davis, and F. D. Davis, "User Acceptance of Information Technology: Toward a Unified View," MIS Quarterly, vol. 27, no. 3, pp. 425-478, 2003, doi: 10.2307/30036540.

[10] V. Venkatesh, J. Y. L. Thong, and X. Xu, "Consumer Acceptance and Use of Information Technology: Extending the Unified Theory of Acceptance and Use of Technology," MIS Quarterly, vol. 36, no. 1, pp. 157-178, 2012, doi: 10.2307/41410412.

[11] D. Al-Fraihat, M. Joy, R. e. Masa'deh, and J. Sinclair, "Evaluating Elearning systems success: An empirical study," Computers in Human
Behavior, vol. 102, pp. 67-86, 2020/01/01/ 2020, doi: https://doi.org/10.1016/j.chb.2019.08.004.

[12] I.-F. Liu, M. C. Chen, Y. S. Sun, D. Wible, and C.-H. Kuo, "Extending the TAM model to explore the factors that affect Intention to Use an Online Learning Community," Computers \& education, vol. 54, no. 2, pp. 600-610, 2010.

[13] A. N. Islam, "Students'e-Learning System Usage Outcomes: A Study with a Learning Management System," in Conference on e-Business, eServices and e-Society, 2011: Springer, pp. 255-268.

[14] J.-W. Lee, "Online support service quality, online learning acceptance, and student satisfaction," The Internet and Higher Education, vol. 13, no. 4, pp. 277-283, 2010.

[15] P. Ratna and S. Mehra, "Exploring the acceptance for e-learning using technology acceptance model among university students in India," International Journal of Process Management and Benchmarking, vol. 5, no. 2, pp. 194-210, 2015.

[16] P. Vululleh, "Determinants of students'e-learning acceptance in developing countries: An approach based on Structural Equation Modeling (SEM)," International Journal of Education and Development using ICT, vol. 14, no. 1, 2018.

[17] J. F. Hair, R. E. Anderson, B. J. Babin, and W. C. Black, "Multivariate data analysis: A global perspective (Vol. 7)," ed: Upper Saddle River, NJ: Pearson, 2010.

[18] R. P. Bagozzi and Y. Yi, "On the evaluation of structural equation models," Journal of the academy of marketing science, vol. 16, no. 1, pp. 74-94, 1988.

[19] B. M. Byrne, Structural equation modeling with AMOS: Basic concepts, applications, and programming. Routledge, 2016.

[20] R. Ho, Handbook of univariate and multivariate data analysis and interpretation with SPSS. CRC press, 2006.

[21] Q. Liao, J. P. Shim, and X. Luo, "Student acceptance of web-based learning environment: An empirical investigation of an undergraduate IS course," AMCIS 2004 Proceedings, p. 377, 2004.

[22] Q. Kharma, "Investigating Students’ Acceptance of Online Courses at Al-Ahliyya Amman University," International Journal of Advanced Computer Science and Applications, vol. 10, no. 7, 2019, doi: 10.14569/IJACSA.2019.0100729.

[23] A. Mehta, N. P. Morris, B. Swinnerton, and M. Homer, "The Influence of Values on E-learning Adoption," Computers \& Education, vol. 141, p. 103617, 2019/11/01/ 2019, doi: https://doi.org/10.1016/j.compedu. 2019.103617.

[24] D. S. Martinho, E. M. Santos, M. I. Miguel, and D. S. Cordeiro, "Factors that Influence the Adoption of Postgraduate Online Courses," International Journal of Emerging Technologies in Learning (iJET), acceptance model; higher education; intention-to-use; online learning. vol. 13, no. 12, p. 123, 2018-12-20 2018, doi: 10.3991/ijet.v13i12.8864.

[25] D. Aijaz Ahmed Arain, Z. Hussain, W. Rizvi, and M. Vighio, "Extending UTAUT2 toward acceptance of mobile learning in the context of higher education," Universal Access in the Information Society, vol. 18, no. 3, pp. 659-673, 07/22 2019, doi: 10.1007/s10209019-00685-8.

[26] N. Samsudeen Sabraz, "University students' intention to use e-learning systems," Interactive Technology and Smart Education, vol. 16, no. 3, pp. 219-238, 2019, doi: 10.1108/ITSE-11-2018-0092.

[27] K. Tamilmani, N. P. Rana, N. Prakasam, and Y. K. Dwivedi, "The battle of Brain vs. Heart: A literature review and meta-analysis of "hedonic motivation" use in UTAUT2," International Journal of Information Management, vol. 46, pp. 222-235, 2019/06/01/ 2019, doi: https://doi.org/10.1016/j.ijinfomgt.2019.01.008. 